\title{
Spectral imaging of Dutch gilt leather for improved conservation strategies
}

\author{
Roger M. Groves ${ }^{1 \star}$, Vassilis M. Papadakis ${ }^{1}$, Martine Posthuma de Boer ${ }^{1}$, \\ Tigran Mkhoyan ${ }^{1}$, Bianca van Velzen ${ }^{2}$, Kate Seymour ${ }^{2}$ \\ 1 Aerospace Non-Destructive Testing Laboratory (AeroNDT), Faculty of Aerospace Engineering, Delft \\ University of Technology, Kluyverweg 1, 2600 GB, Delft, The Netherlands \\ 2 Stichting Restauratie Atelier Limburg (SRAL), Avenue Ceramique 224, 6221 KX Maastricht, The \\ Netherlands \\ * Corresponding author: R.M.Groves@tudelft.nl
}

\begin{abstract}
Gilt leather was one of the most fashionable and costly types of wall-hangings in the Western world in the $16^{\text {th }}$ to $18^{\text {th }}$ centuries. It has a gold appearance which is the result of a silver leaf coated with an orange-brown varnish. It is a layered composite of organic and inorganic materials, including leather, animal glue, silver metal-leaf, varnish, and oil paint. Ageing processes are complex due to many interactions between these different materials, which makes conservation a real challenge. Furthermore, the common conservation treatments practiced in the past resulted in negative side-effects over-time such as gloss and colour change (darkening) and stiffening of the support. Hyperspectral imaging is a proven non-destructive method that has been used in conservation for more than two decades, mostly for the examination of paintings and manuscripts. With its use, it is possible to reveal features and their locations invisible to the naked eye, such as thin varnish layers, paint and overpaints or underdrawings.

In this study, a collection of gilt leather objects was studied at SRAL. Data were analysed using a software analysis platform (TIPP), developed at AeroNDT. The results show maps of quantitative pigment concentration and areas with possible chemical degradation or silver tarnishing.
\end{abstract}

Keywords: hyperspectral imaging, gilt leather, conservation, non-destructive testing, Dutch cultural heritage

\section{Introduction}

Gilt leather was one of the most fashionable and costly types of wall-hangings in the Western world from the $16^{\text {th }}$ to the $18^{\text {th }}$ centuries. The origins of this particular decorated leather lie in North-Africa (Ghadames, Libya). The craft spread through Spain towards the rest of Europe in the late Middle Ages. In the mid-1 $17^{\text {th }}$ century Dutch gilt leather had a similar fame to Delftware and Dutch paintings.

In The Netherlands, only 60 gilt leathers have survived in-situ in historic houses, castles, palaces, churches, town halls and other public or private institutions [1]. This is 
only a small percentage of what once existed. Archival research revealed that in Leiden, just on the Rapenburg alone, one of the main canals of the city, 60 rooms were decorated with gilt leather in the $17^{\text {th }}$ and $18^{\text {th }}$ centuries. None of these have survived. Due to the complex nature and sensitivity of the material, conservation of gilt leather is a challenge. Former craft-led conservation practices, focused solely on either the leather support or the decorative surface layers, negating the fragility of the separate materials used and the complexity of the layer build-up. As a consequence, a considerate amount of gilt leather ensembles and objects are in an alarming condition today.

Gilt leather is a layered composite of organic and inorganic materials. The aging of gilt leather is characterised by the specific degradations of each of the materials and the possible interactions between them. Typical chemical and physical damage and degradation processes have been studied for each of the materials - leather, animal glue, silver leaf, varnish, oil paint - and presented within the literature of the different conservation disciplines: leather, metals and paintings conservation. For example, much has been published on the complex ageing of leather [2, 3], as well as the degradation of oil paint [4]. However, there is scarce literature on the specific degradations of the composite materials of gilt leather or their interactions with each other. While the materials composing the aesthetic layers are often similar to oil paintings, the layer build-up of the laminate structure for gilt leather is opposed to traditional paintings practice as the varnish layer is found below the coloured paint. This leads to more complex problems in terms of cleaning these delicate surfaces with solvents. As a result, in the past many gilt leather ensembles were irrevocably damaged. The problem regarding the ageing and conservation of gilt leather has recently been brought to the attention in a white paper [5]. Some projects start taking into account possible interactions between the different materials and the resulting degradation products. Key to this new approach for the conservation of these precious beautiful ensembles is identifying the problem. This is where hyperspectral imaging can play a role, providing conservators with the appropriate diagnostic tools and resulting in data with which it will be possible to make suitable and ethical decisions for future treatment.

Hyperspectral Imaging (HSI) is an optical technique that holds the potential in characterising materials and degradation phenomena by their optical properties, or in determining and visualising mechanical properties and behaviour of materials, including defects. Within the domain of art history, archaeology and conservation, hyperspectral imaging has been used since the 1990s, mostly for the examination of paintings and manuscripts [6]. It has proved to be a successful tool for revealing things that are invisible to the naked eye. The near infrared spectrum (700-2500 nm) can be used for revealing underdrawings situated beneath opaque paint layers. To make faded writing in manuscripts visible, UV-reflected light and certain infrared bands are used. Retouchings can be made visible this way; moreover, their contrast reflectance pattern/ spectra is different under divergent light sources. Hyperspectral imaging can also be of use in the monitoring of conservation treatments. For example, monitoring the laser cleaning intervention on marble crusts $[7,8]$. This technique has also proved applicable for monitoring the partial cleaning of (yellowed aged) varnishes [9]. Another interesting application is pigment charac- 
terisation, which unfortunately remains complicated, as some pigments do not have very distinct spectral features, for instance yellow pigments [10]. The characterisation of pigment mixtures present in decorative paints is an even more demanding challenge; however, success is possible [6]. Deterioration analysis of painted surfaces using HSI focuses on the determination of the areas under risk based on the combined information deriving from both mechanical and chemical changes $[11,12]$.

Preliminary non-destructive analyses were performed with hyperspectral imaging (at AeroNDT) in order to get a better understanding of specific degradation phenomena taking place within the decorative layers. Understanding the data set provided during the preliminary study allowed researchers to progress to case studies. These were provided by SRAL. The case studies consisted of 5 sections of gilt leather ensembles currently undergoing treatment in the Maastricht conservation studios, of which the results of the panel from the Maastricht Town Hall will be presented here.

\section{Materials and methods}

The gilt leather sections were analysed using the modular 3D hyperspectral imaging scanner setup developed at AeroNDT, see Fig. 1. Particularly:

\subsection{Hyperspectral imaging}

The hyperspectral imaging system used was a line-scan spectral camera (IMSPECTOR V10E, Specim $\odot$ ) with a wavelength sensitivity range of 400-1000 $\mathrm{nm}$. The camera was attached to a 3D scanning system, as described in the following section. The

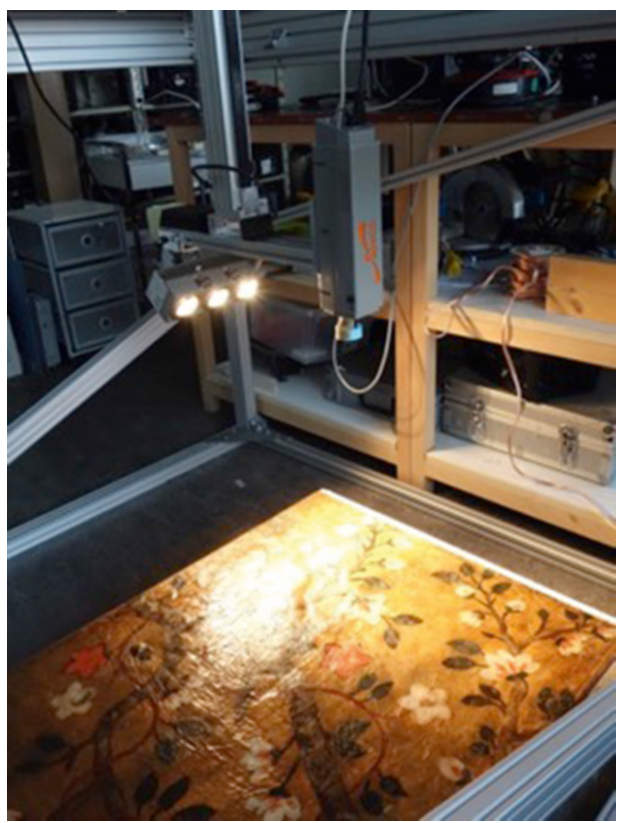

Fig. 1. The hyperspectral camera and light sources mounted on the modular 3D hyperspectral imaging scanner, developed at AeroNDT. Close-up of the setup in the conservation studio at SRAL. The gilt leather wall-hanging panel comes from the Town Hall in Maastricht.

objective lens of the camera was set to image a line of spatial information with a size of approximately $10 \mathrm{~cm}$. The frame rate of the camera was set to $3 \mathrm{fps}$ with a shutter time of $333 \mathrm{msec}$. The light sources were installed under a 45 degree angle with respect to the surface plane. The sample's surface temperature before measurements was measured and tests were performed related to the maximum temperature rise of the samples surface within 1 hour of illumination.

The calibration of the hyperspectral system was achieved by a white diffuse reflectance target made out of Spectralon (SRT-MS-050, Laser2000) and a dark reference image that was obtained with the shutter closed. Prior to the measurements, 
reference images were acquired from the white target, and with the camera's shutter closed. The white reference image contains much of the information needed for the calibration since it contains information related to the spectral variations of light, together with the differences deriving from the light source and optics. The image with the shutter closed contains the dark current background, which is subtracted from the signal image as it contains an offset. It should also be noted that the white and dark reference signals also contain a random noise component, so the calibration procedure slightly increases the overall signal noise.

\subsection{Scanning system}

The spectral camera is coupled to a $3 \mathrm{D}$ scanning system, which is a 3 axis Cartesian coordinate robot, capable of moving at maximum speed of $8 \mathrm{~cm} / \mathrm{s}$ in XY-axis and 5 $\mathrm{cm} / \mathrm{s}$ in Z-axis. The drive system and chassis are comprised of toothed-belt Linear Motion stages (MAXR23-S42-H42-C42, Schneider Electric) and are capable of delivering 0.05 $\mathrm{mm}$ repeatability. The chassis is motorised by means of 3 stepper motors/controller duo, the (QSH6018-86-28-310 and PD4-11360-SE-485, Trinamic Motion). The encoder allows micro-stepping and provides resolutions of up to 2.3 micron in the $\mathrm{X}$ - and Y-axes and 1.5 micron in the $\mathrm{Z}$-axis. The system is augmented with a Neugart planetary gear system of PLE 060 Series. Additionally, the $\mathrm{Z}$-axis is equipped with a mechanical brake and allows payload carrying capability of up to $12 \mathrm{~kg}$. The scanner assembly rests on a lightweight frame constructed with extruded aluminium beam members and perforated steel fortification elements to limit shearing. The scanner measures $1400 \mathrm{~mm}$ in $\mathrm{X}$ - and Y-, and $1200 \mathrm{~mm}$ in Z-axes. The active scanning volume, determined by the X-, Yand $\mathrm{Z}$-axis travel, is $785 \mathrm{~mm}, 895 \mathrm{~mm}$ and $500 \mathrm{~mm}$ respectively. Due to the additional elements (spectral camera and light source), the resulting bracket system was relatively large and limited either the X- or Y-axis travel by approximately $200 \mathrm{~mm}$. Finally, the entire setup is modular and can be dismantled and carried by two individuals.

In the current study, the modular 3D hyperspectral imaging scanner setup was initialised accordingly to the gilt leather sections. The main travel axis was limited to a speed of 0.0738 centimetres per second to match the camera acquisition speed. Hence, the larger pieces of guilt leather required several hours of scanning. Particularly large surfaces were scanned over the course of two days to prevent any damage that would be caused by the heat from the light source.

\subsection{Case Study: Chinoiserie gilt leather wall-hangings in the Mayor's office of the Town Hall of Maastricht}

Data presented in this paper, deriving from the hyperspectral images, were obtained from the $65 \mathrm{~cm}$ by $10 \mathrm{~cm}$ scanned section of gilt leather wall-hangings from the Town Hall in Maastricht. The section scanned was selected from the $178 \mathrm{~cm}$ by $71 \mathrm{~cm}$ panel removed from the interior setting (Fig. 2 and Fig. 3) for a pilot conservation and restoration project at SRAL in 2014-2016.

The panel is part of a larger ensemble that covers the four walls of the Mayor's office in the Town Hall. The Dutch architect Pieter Post (1608-1669) and his local assistant Cornelis Pessers designed and built the Town Hall in Maastricht between 1655 and 1662. Archival evidence dates the gilt leather wall-hangings to some seventy-five years later to the late 1730s. The Maas- 

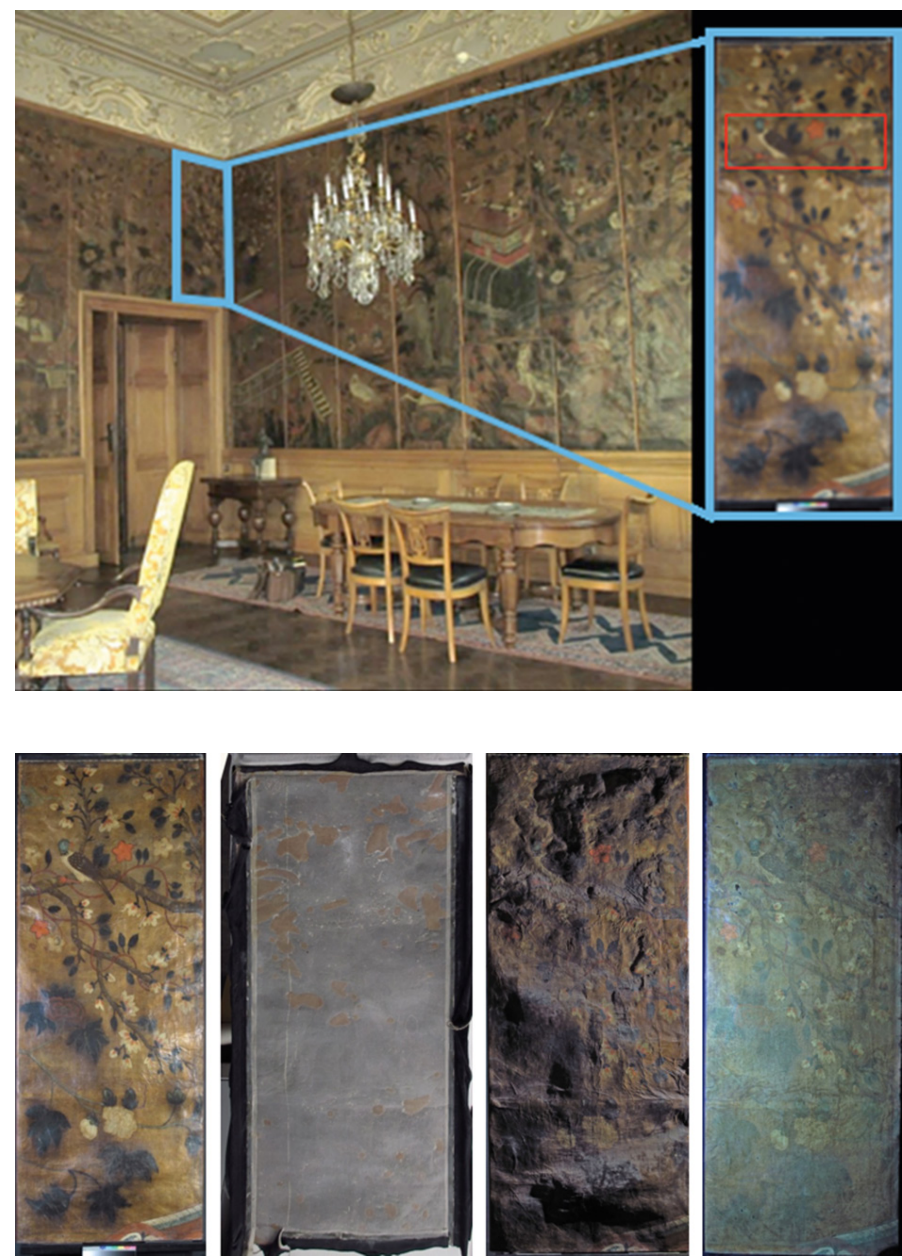

Fig. 3. The $18^{\text {th }}$ century English gilt leather panel $(178 \mathrm{~cm} \times 71 \mathrm{~cm})$ from the Town Hall in Maastricht. Left: front view in visible light; left centre: reverse view in visible light; right centre: front view in oblique/raking light; right: front view in ultraviolet light. @ SRAL
tricht-Brabant Mayor Godaert van Sleypen commissioned the ensemble in 1737 , via the cabinetmaker Van Thiel in The Hague, from an English manufacturer of gilt leather hangings [13]. The vertical panels depict a continuing, non-repeating oriental landscape painted in a "Chinoiserie" style. The pattern is unique and few other ensembles in this Chinoiserie style remain worldwide. Though manufactured in England, the Maastricht gilt leathers conform to Dutch production techniques, although the pattern is not embossed. As such, the ensemble can be described as a "flat type" of gilt leather. The layer build-up, seen in cross-sections (Fig. 4), consists of the (1) leather support, (2) silver leaf, (3) a "gold-coloured" varnish, and $(4,5)$ oil paint decorative layers.

The ensemble was treated at least three times in the past. The earliest documented treatment took place in 1861 by Mr. J. Krans, the second in 1927-1928 by Mr. Jan Mensing, and the latest around 1970 by Mr. H.A.B. van Soest. The current surface appearance is a result not only of original materials, but also of those left during past restoration cam- 


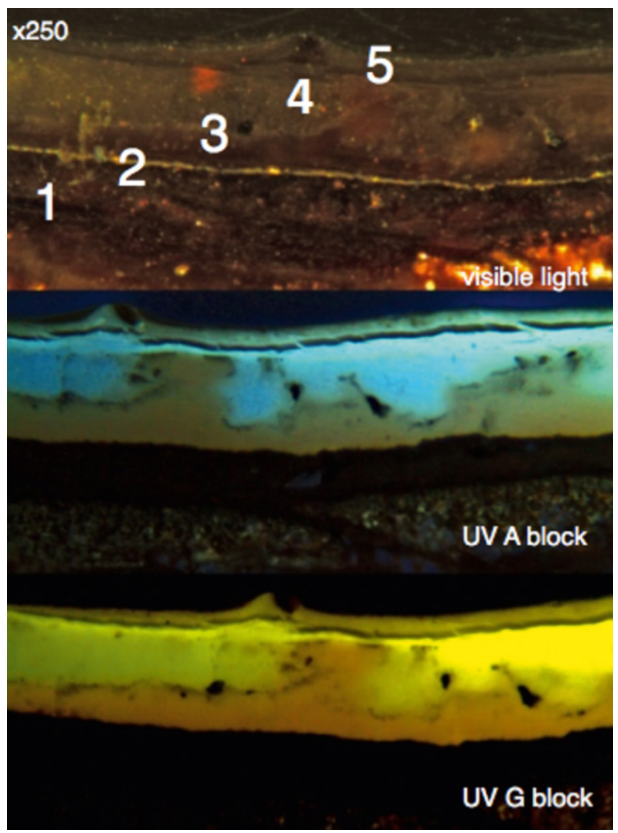

Fig. 4. Cross-section (MG4) removed from Maastricht Town Hall $18^{\text {th }}$ century English gilt leather showing representative layer build-up of manufacture process and materials. Magnification: 250×. Top: visible light; Middle: UV A block filter; Bottom: UV G block filter. The sample shows (1) leather support; (2) silver leaf; (3) a "gold-coloured" varnish; (5) non-original varnishes and dirt layers. The sample was removed from an area without decorative paint layers. Remnants of the original yellow coloured varnish layer can be seen migrating into more recently applied varnish layers. @ SRAL

paigns. Previous cleanings removed, partially or in some areas completely, the original orange-brown coloured varnish layer, and restorations added additional modern (coloured) varnish layers. Treatments carried out in the earlier documented restorations are not fully described. The report by Van Soest gives few details about the treatment of the pictorial layer, though it seems that his intension was to achieve a matte non-glossy surface and he retouched damages [14]. It is known that Van Soest consulted Mr.
H.S. Bloedhouwer, a restorer at the Rijksmuseum, Amsterdam. Bloedhouwer provides a piece of advice in Rapport betreffende restauratie goudleerbehang in het Raadhuis van de gemeente Maastricht ${ }^{*}$. He suggests that the vertical joints between the leather panels are re-stitched, the front is cleaned and paper/ glue backings on the reverse are removed. The leather support should be made more supple by massaging in a leather dressing ('...om een weinig leven in het leer terug te brengen...'), and the tears in the support should be mended by gluing leather patches and covering these with Tergal (polyester) fabric. It appears that Van Soest followed most of this advice. The stitched borders have been removed and replaced by new strips of leather, a Lycra fabric was adhered to the edges of the panels to provide flexible tensioning, old patches removed and replaced as suggested, a thin polyester gauze (Tergal) was glued using Mowilith (PVA) dispersion to the reverse of the original leather support, and finally the leather panels were stretched around double-sided aluminium honeycomb supports for additional strength.

Diagnosing the condition of the original surface-decorative materials, the extent of later restoration additions, and their effect is essential for determining conservation strategies and proved problematic due to the current surface appearance (Fig. 5). The surface was very dirty and dust had accumulated in deformations caused by a lack of tension across the support. "Flat-type" gilt leather

* The treatment proposal by H.S. Bloedhouwer was provided after a visit to the Mayor's Office at the Maastricht Town Hall on 21 November [1967]. Van Soest, H.A.B., Behandelingsvoorstel (Treatment proposal) 'Maatrichtse goudleer', C.L. dossier Maastricht, gemeentehuis: goudleer 67/3A 745.531.025, 1 page and photograph from the dossier $67 / 3$. 


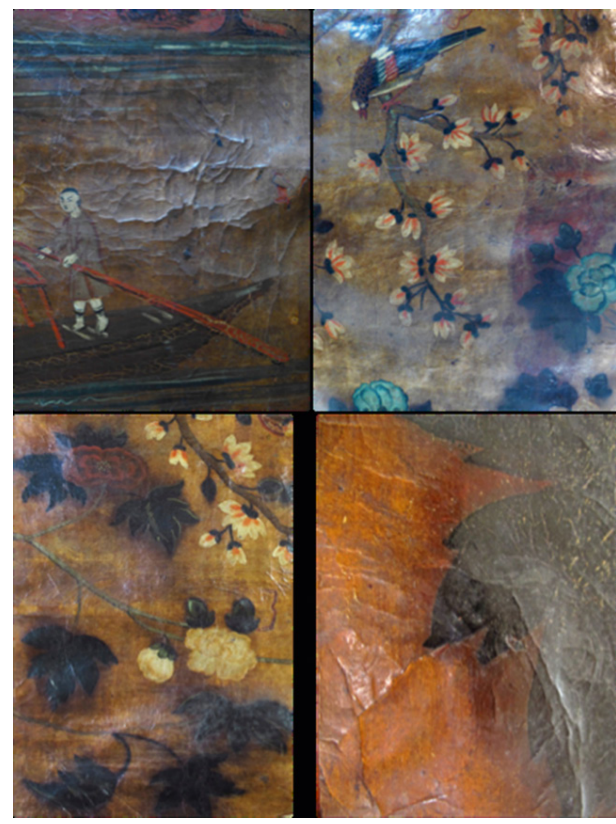

Fig. 5. Four images showing various surface deterioration and degradation effects. Top left: dusty surface and cracks in the leather support; top right: discoloured modern varnish layers muting original decorative scheme; bottom left: blackening of green leaves and dark surrounding halo; bottom right: detail of bottom left where the silver leaf has been tarnished. (C) SRAL

surfaces were often a contrast between matt (paint) and glossy areas (gilt background). This interplay of surface appearance is no longer apparent. The upper (later) varnish layers were applied indiscriminately over background and decorative areas. These had discoloured, changing the hue and tone of the original pictorial layers. The varnish layers have also become very glossy. The illusion of depth and the vivid colours of the composition are no longer apparent. Micro-fissures and cracks have propagated from the support through the varnish layers further disrupting the legibility of the image. Micro-chemical interactions between pigment, binding media, metal leaf and oil-resin varnish have caused the green leaves to become almost black in colour. Past cleaning solutions had dissolved paint, dispersing orpiment pigment particles from the green leaves over exposed areas of the silver leaf, exacerbating the tarnishing of this material. The visible appearance of the degradation results in a dark halo surrounding the leaves.

Visual observations using magnification and selective sampling of the surface aided the conservators in mapping original and non-original materials. Sampling confirmed the traditional layer build up and gave insight into pigment use. This was facilitated using traditional photographic documentation techniques employing lights of different wavelengths (ultraviolet, infra-red reflectography and $\mathrm{x}$-radiography). The traditional documentation techniques were supplemented by the results of the hyperspectral imaging carried out in conjunction with the AeroNDT team. Results aided the conservators in understanding the complex laminate structure and the (conservation) history of the object.

Hyperspectral imaging of the Maastricht gilt leather panel took place during a later phase in the conservation process. Initial surface cleaning had occurred and the aesthetical improvement (retouching) of the decorative image was completed. Optimally, HSI should take place during the initial diagnostic study and can be used throughout the treatment campaign to establish effective cleaning results. The removal of all remnants of non-original materials would provide a complete study of the original surface; however, in reality compromises are essential as often it is not ethically possible to remove all non-original material from delicate surfaces. Interpreting the images provided by the HSI would be 
difficult due to the complexity of materials on the surface. This challenge would allow the research team to establish protocol and parameters of the imaging system.

The presence of modern varnish layers on the Maastricht Town Hall gilt leather panel, applied in the 1970s/1980s, is clearly visible in the cross-sections (Fig. 4). The modern varnish was applied over the whole surface, including the pigmented layers, and had unknown additives (plasticisers or solvents) that caused the underlying original orangebrown varnish to migrate up into the newer varnish. The conservators had removed dust and dirt layers from the surface, and where safe had partially thinned the non-original modern varnish layers from non-decorative areas. It was not deemed safe to remove the varnish from the decorative layers due to the lack of interface between varnish applications. The conservators hoped that the hyperspectral scan would pin-point with greater accuracy areas presenting this problem. Then, a more accurate cleaning strategy could be implemented for the rest of the ensemble.

The second issue that the conservators desired was the clarification regarding the extent of tarnishing around the green leaves. Scanning electron microscopy linked with energy dispersive $\mathrm{x}$-ray spectroscopy (SEM-EDX) showed that the green paint is composed of a mixture of blue and yellow particles. The very fine blue particles could not be easily identified but contained the elements iron $(\mathrm{Fe})$ and aluminium $(\mathrm{Al})$; the yellow particles contained arsenic (As) and were therefore expected to be orpiment (arsenic sulphide $\mathrm{As}_{2} \mathrm{~S}_{3}$ ). Combinations of ultramarine (a pigment containing the elements iron and aluminium) or indigo and orpiment were common in the $18^{\text {th }}$ century to produce green coloured paint. The morphology of the pigment particles indicates a use of indigo (precipitated to an alum base) rather than ultramarine. An early use of Prussian blue is also possible as the manufacture of the pigment was widespread by 1730 (first publication in England in 1724). Cross-section samples removed from the area surrounding the leaves showed that particles of orpiment pigment had spread across the decorative borders. It is those, combined with atmospheric pollutants and solvents when applying the modern varnishes, which have probably caused the tarnishing. Conservators hoped to obtain an accurate map of the extent of tarnishing using the hyperspectral scanning system.

\subsection{Processing and analysis software}

Processing and the analysis of the gilt leather measurements were performed with an advanced image-processing platform (TIPP) that was developed at AeroNDT [15]. Initially, measurements are processed for calibration with the reference images in order to achieve repeatable and comparable data. This is simply achieved by subtraction of the dark reference and normalisation with the white reference. Data are processed through 32 bit floating point variables, which ensures that no data are lost from the calculations. Following calibration, the user has the option to process data to correct for the aspect ratio due to the acquisition properties, for dimension reduction, and for image stitching from multiple measurements. Advanced analysis algorithms are focused on principal component analysis (PCA) and on reference component analysis (RCA), which is based on non-negative least squares solutions for un-mixing spectral features of pixels. Viewing of data is achieved with a novel module that allows multi-dataset visualisation of spectral 
data and of the analysis results. Moreover, spectral reflection characteristic graphs can be visualised and exported from a single point of view after averaging with multiple different methods.

\section{Results}

\subsection{Surface temperature measurements}

The surface temperature of the scanned section, see Fig. 6, was initially measured with no illumination at 20.2 degrees Celsius $\left({ }^{\circ} \mathrm{C}\right)$. After one minute of exposure, the temperature rose to $22.3^{\circ} \mathrm{C}$, which was the most

\subsection{Gilt leather section measurements}

A $10 \mathrm{~cm}$ by $65 \mathrm{~cm}$ gilt leather section from the Maastricht Town Hall panel was examined and scanned. Measurements were performed across the whole sensitivity range of the sensor, starting at $400 \mathrm{~nm}$ and up to $1000 \mathrm{~nm}$ in the near infrared region. The total of spectral images acquired in this region were 196 bands, resulting to a tuning step of approximately $3 \mathrm{~nm}$. The dynamic range (bit depth) of the sensor was set to be 12 bit equivalent to 4096 grey levels.

Six different points of interest were selected as representative of the different

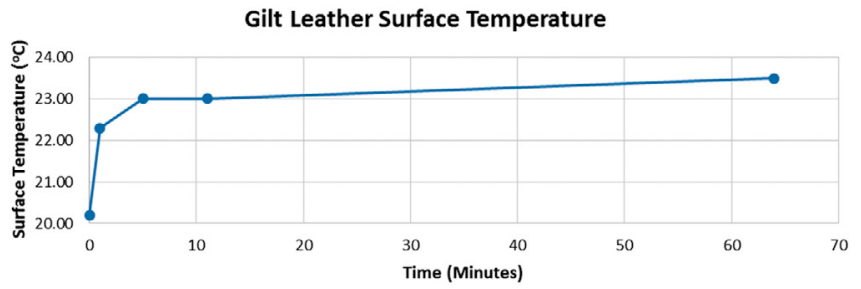

Fig. 6. Gilt leather surface temperature rise measurements. Temperature remains almost constant after 5 minutes of exposure in the systems light source.

significant raise in temperature observed. In the subsequent 5 minutes of illumination, the temperature reached $23.0^{\circ} \mathrm{C}$, where it remained almost constant for a full hour of measurements. The surface temperature was measured at $23.5^{\circ} \mathrm{C}$ after 65 minutes of exposure to the light source. The $3.3^{\circ} \mathrm{C}$ temperature increase was deemed minimal and not damaging to the gilt leather panel and its constituent materials. materials present on the surface of the gilt leather panel. These points were selected based on visual inspection and are shown in Fig. 7. The reference points were chosen where the decorative surface appeared to be most homogeneous and dense. As presented in the following Fig. 8, the reflection spectrums from each point were extracted Fig. 8 and recorded in TIPP database to be later used as reference points for the RCA.

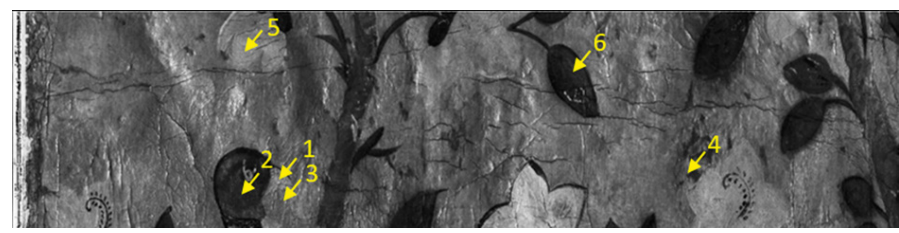

Fig. 7. Imaging at $700 \mathrm{~nm}$ of gilt leather section from the Maastricht Town Hall. The points of interest that were selected for spectral reflection characteristics extraction are displayed. 


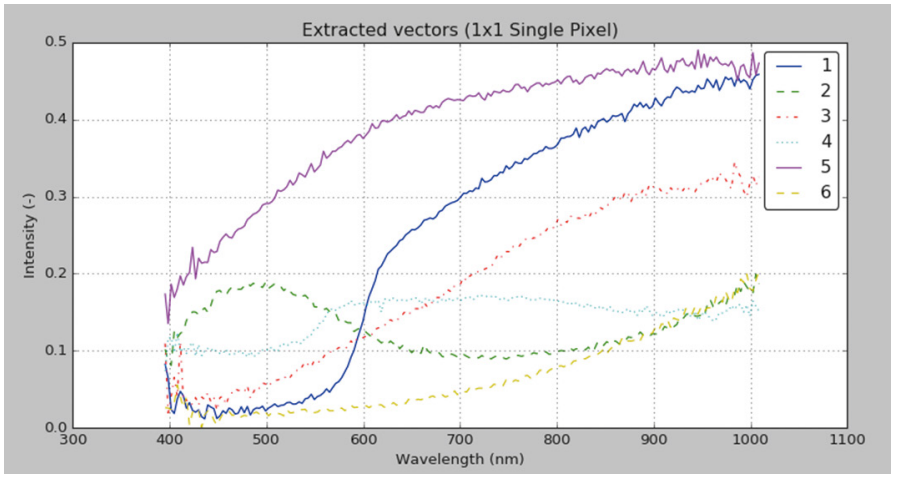

Fig. 8. The reflection spectral characteristics as displayed from the reference points selected in TIPP viewer. (1) red paint; (2) blue paint; (3) gold varnish; (4) white paint; (5) white-grey paint; and (6) green paint.
The reference points that were selected included: (1) red paint; (2) blue paint; (3) gold varnish; (4) white paint; (5) white paint with underlying corrosion; and (6) green paint. It is expected that the reference points selected contain for the paints more than one pigment and or a contribution from under-layers, such as the gold varnish and the silver leaf layers. Spectra obtained from similarly coloured surfaces may thus appear different. Ultimately, cross-section removed from the reference spectra points would aid in interpreting spectra and contrast false-colour images obtained at different wavelengths. Cross-section analysis and interpretation for the Maastricht Town Hall are reported elsewhere [16].

Following extraction of reference spectral characteristics, analysis was continued with RCA, which resulted in the mapping of the specific spectral characteristics in unique image maps. In Fig. 9, a colour image of the scanned area, shows the points where the 3 reference spectral characteristics were extracted from the blue, green and red coloured paint. After the RCA was completed, the scientists and conservators selected the 3 vectors of the main paints, as shown in Fig. 9, to create the false-colour image in Fig. 10, of the selected paint distribution. Each of those 3 image maps contain quantitative information related to the percentage of contribution of each reference.

\subsection{Interpretations}

Interpreting the resulting hyperspectral maps of the painted gilt leather panel from the Maastricht Town Hall proved challenging. The scans clearly show different spectral

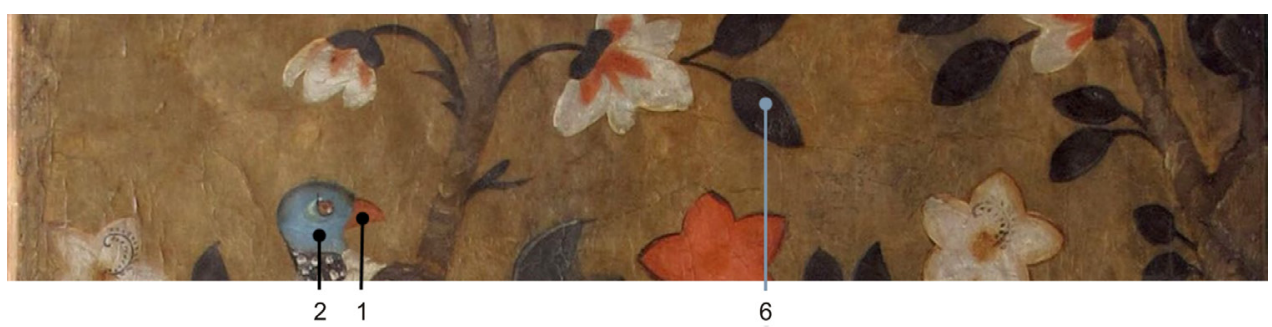

Fig. 9. Colour image from the Maastricht's gilt leather section. With numbers, the reference components that were used for further analysis are shown. 


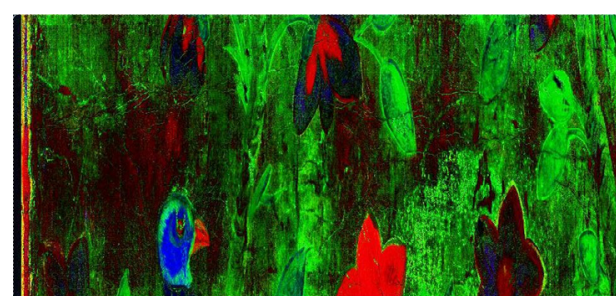

Fig. 10. The resulting false-colour image that was created by merging the reference component maps from the RCA. The false-colours represent: blue refers to the blue paint, green to the green paint, and red to the red paint.

responses to the different components used within the artwork (silver leaf, varnish, and paints). Studying the false-colour maps extracted at different wavelengths aided the differentiation of materials. Different paint mixtures in varying concentrations could be readily mapped, such as the blue colour of the bird's head and the red paint used for the flowers and the bird's beak. SEMEDX analyses of cross-sections confirmed a mixture of indigo (or Prussian blue) and lead white for the blue paint and a mixture of vermillion and minium for the red paint. The spectral response of a component in the paint of the white flowers (point 4, Fig. 7) is similar to the blue paint (point 2, Fig. 7), and is thus imaged in a similar shade of blue in the false-colour image (Fig. 10). The spectral response, at this wavelength represented in Fig. 10, of the blue paint of the bird's head is different from the paint applied around the outline of the head, which has similarities to the green paint mixture of the leaves. The spectral curves for the two white reference points (curve 4 and 5, Fig. 8) are dissimilar. This can be explained due to differences in layer build-up of the paints or a percentage difference in the concentration of pigment particles in these similarly appearing white flowers.
Prior SEM-EDX analyses of cross-sections pointed out that the green paint of the leaves is a mixture of orpiment and either indigo or Prussian blue. The false-colour maps show that, in the "golden" background, materials are present that have similar spectral characteristics as the green leaves. This could either correspond to orpiment particles that have been spread over the surface, or to silver corrosion, or both. HSI analyses on other gilt leather samples have shown that reference vectors taken from green paints tend to be difficult to differentiate from those taken from corrosion of the silver leaf. Both show a strong absorbance in the NIR. The visualisation of the extent of tarnishing of the silver leaves, due to the presence of arsenic sulphide (orpiment) thus remains ambiguous.

Imaging under higher optical magnification (3 cm field of view) was performed in selected areas where silver corrosion was visible under visual inspection. It was found that mapping of different corrosion levels is possible, and a broader spectral range (beyond 1000nm) could help in the differentiation between corrosion products of the silver leaf.

Subtle differences between similar materials were not as easily differentiated. The majority of the surface, mainly the gold coloured background, was composed of materials with similar chemical characteristics (organic natural resin varnishes) that, though applied at different times, gave similar readings throughout the spectral range used. It was not possible to delineate between areas where the upper varnish layers had been partially removed (coloured figurative areas) from those where the upper varnishes had not been removed (non-figurative areas). Nor was it possible to map where the original orange-brown varnish had migrated into the later applied varnish. 


\section{Conclusions}

In this study, the authors have shown that hyperspectral imaging can be a very useful tool for the diagnosis of gilt leather panels, as shown by the Maastricht Town Hall case study. The HSI of the surface did aid conservators in understanding the object more fully. Therefore, the technique can be a useful non-destructive tool in information gathering both prior to and during conservation treatments, and can be used in conjunction with micro-sampling to assist in understanding laminate build-up. A better understanding of the object and its constituent materials leads to a more informed decision-making process for determining conservation treatment strategies. In the case discussed, pigment characterisation was easily performed and image maps containing quantitative information regarding the pigment concentration was achieved. It was found that mapping of specific degradation phenomena, such as silver corrosion, requires high spatial resolution (approximately $30 \mathrm{um}$ ) and is still a challenge as material dynamics are complex. Specific pigment characterisation, deterioration analysis and mapping would become possible by the use of a database with reconstructions and reference samples, which is currently under development.

Further development on both hardware and software platforms will continue to enable the use of such technology in multiple fields of conservation without the limitation of the size of artwork. Furthermore, the scanner can be equipped with a wide variety of NDT specific measuring equipment, using the custom tailored brackets that will allow for multi-sensor measurements. One example is the combination of hyperspectral imaging with optical coherence tomography [17]. The TIPP platform is also progressing in such a direction to accept data from those sensors, and with advanced data-fusion techniques to enable analysis of the artwork from a single software tool.

\section{Acknowledgements}

The gilt leather project is funded by the Netherlands Organisation for Scientific Research (NWO) and is part of the Netherlands Institute for Conservation, Art and Science (NICAS).

\section{References}

[1] E.F. Koldeweij Goudleer in de Republiek der Zeven Verenigde Provinciën. Nationale ontwikkelingen en de Europese context. Leiden: Proefschrift ter verkrijging van de graad van Doctor aan de Rijksuniversiteit te Leiden 1998.

[2] R. Larsen ed. Environment Leather Project. Deterioration and Conservation of Vegetable Tanned Leather. Protection and conservation of European cultural heritage. Research Report Nr. 6. Copenhagen: 1996.

[3] R. Larsen "Experiments and observations in the study of environmental impact on historical vegetable tanned leathers". Thermochimica Acta, 365 (2000) 85-99, DOI: 10.1016/S0040-6031(00)00616-X.

[4] A. van Loon, P. Noble, A. Burnstock "Ageing and deterioration of traditional oil and tempera paints", in: Hill Stoner, J., R. Rushfield (Eds.) Conservation of easel paintings, Oxon 2012.

[5] M. Posthuma de Boer, E.F. Koldeweij, R.M. Groves, Gilt leather artefacts. White Paper on Material Characterization and Improved Conservation Strategies within NICAS, Delft 2016.

[6] H. Liang "Advances in multispectral and hyperspectral imaging for archaeology and art conservation", Applied Physics A, 106 (2012) 309-323, DOI: 10.1007/s00339-011-6689-1.

[7] V.M. Papadakis, A. Loukaiti, P. Pouli. "A spectral imaging methodology for determining on-line the optimum cleaning level of stonework", Journal of Cultural Heritage, 11 (2010) 325-328, 2010, DOI: 10.1016/j.culher.2009.10.007. 
[8] V.M. Papadakis, Y. Orphanos, S. Kogou, K. Melessanaki, P. Pouli, C. Fotakis, "IRIS: a novel spectral imaging system for the analysis of cultural heritage objects", Proc. SPIE 8084 80840W (2011), DOI: $10.1117 / 12.889510$.

[9] M. Kubic "Hyperspectral Imaging: A New Technique for the Non-Invasive Study of Artworks", in: Creagh, D., D. Bradley (Eds.), Physical Techniques in the Study of Art, Archaeology and Cultural Heritage, Elsevier 2007, pp. 200-259.

[10] S. Kogou, A. Lucian, S. Bellesia, L. Burgio, K. Bailey, C. Brooks, H. Liang,"A holistic multimodal approach to the non-invasive analysis of watercolour paintings", Applied Physics A, 121 (2015) 999-1014, DOI: 10.1007/s00339-015-9425-4.

[11] L.G. Montagud, C. Portalés, B.P. Carbonell, E.R. Gómez, A.G. Lucas, V. Tornari, V. Papadakis, R.M. Groves, B. Sirmacek, A. Bonazza, M. Föster, P. Aswendt, A. Borreman, J.D. Ward, A, Cardoso, L. Aguiar, F. Alves, P. Ropret, J.M. Luzón-Nogué, C. Dietz, "Deterioration estimation of paintings by means of combined 3D and hyperspectral data analysis", Proc. SPIE 8790 (2013) 879008, DOI: 10.1117/12.2020336.

[12] L.G. Montagud, C. Portalés, B.P. Carbonell, E.R. Gómez, A.G. Lucas, V. Tornari, V. Papadakis, R.M. Groves, B. Sirmacek, A. Bonazza, M. Föster, P. As- wendt, A. Borreman, J.D. Ward, A, Cardoso, L. Aguiar, F. Alves, P. Ropret, J.M. Luzón-Nogué, C. Dietz, "SYDDARTA: new methodology for digitization of deterioration estimation in paintings", Proc. SPIE 8790 (2013) 879011, DOI: 10.1117/12.2020333.

[13] E.F. Koldeweij, "Het goudleer-behang in de burgemeesterskamer in het stadhuis van Maastricht", Een seer magnifiek Stadthuys. Tien studies over de bouw en de inrichting van het stadhuis te Maastricht, Delft 1985, pp. 151-159.

[14] Van Soest, H.A.B., "Het goudleer en haar restauratie" (1969?1971?). C.L. dossier Den Haag, Gemeentemuseum: goudleer 70/2 745.531.025, 2-14 en $2-2$ p.13 en 14.

[15] TU Delft Image Processing Platform, http:// www.lr.tudelft.nl/TIPP (accessed 22.09.2016).

[16] B. van Velzen "Goudleer Maastricht Stadhuis vooronderzoek pilot: onderzoeksresultaten en behandelingsvoorstel" Internal report SRAL 2016.

[17] L.M. Dingemans, V.M. Papadakis, P. Liu, A.J.L. Adam, R.M. Groves. "Optical coherence tomography complemented by hyperspectral imaging for the study of protective wood coatings", Proc. SPIE. 9527, Optics for Arts, Architecture, and Archaeology V (2015), 952708, DOI: 10.1117/12.2184716. 
